\title{
Alternative Telecasts and the Ongoing Fracturing of Sports Television
}

Branden Buehler

This is the accepted manuscript version of the article published as: Buehler, Branden. "Alternative Telecasts and the Ongoing Fracturing of Sports Television." Journal of Sports Media, vol. 15 no. 2, 2020, p. 117-135.

The published version of the work is available at the following link: https://muse.jhu.edu/article/787268

\begin{abstract}
Several sports media companies have recently experimented with expanding their television coverage of major events across multiple outlets, offering traditional telecasts on their flagship channels while adding alternative telecasts on secondary outlets. Significantly, unlike most "second screen" experiences, the alternative telecasts offered on secondary outlets have largely been meant not to complement the traditional telecasts, but rather to substitute for them. In order to better understand what this new model of sports telecasting means for the present and future of sports television, this article is split into two parts. First, the article traces the rise of alternative telecasts, in the process distinguishing them from second screen experiences and explaining their industrial origins. Second, the article examines how alternative telecasts contribute to the ongoing fracturing of sports television and, in the process, both continue to erode the communal engagement of sports television and reshape the genre's relationship to its audiences.
\end{abstract}




\section{Alternative Telecasts and the Ongoing Fracturing of Sports Television}

Sports television has recently evolved into a multi-platform affair. Audiences are now frequently expected to watch games on their televisions while simultaneously using other devices to check their fantasy teams or social media feeds - a viewing experience that Victoria E. Johnson (2009a) has referred to as a "unique hybrid ... between network television's traditional role as the site of 'mass' audience ... and the post-network era's characteristic proliferation of content and its co-branded migration between media forms" (p. 116). In the past several years, though, sport's "unique" hybrid status has come into question as several networks have launched experiments focused not on second screen integration, but rather on creating primary screen alternatives. Fox, for example, has experimented with an alternative baseball telecast solely devoted to statistical analysis, while Turner has rolled out college basketball "TeamCasts" meant to cater to specific fanbases. ESPN, meanwhile, has committed to the alternative telecast model with even more zeal, as it has covered an increasing number of events by overflowing its many outlets with niche content. For example, during the 2020 College Football Playoff National Championship, played between Clemson University and Louisiana State University, ESPN aired a traditional game telecast on its flagship channel while simultaneously using numerous other ESPN outlets to feature unconventional alternatives. ESPNU, for instance, aired a "Coaches Film Room" telecast spotlighting analysis from several college football coaches, while ESPN3, ESPN's internet streaming service, featured options like a "DataCenter" telecast emphasizing statistical analysis.

With the rise of these new alternative telecasts the sports television text has become split in unprecedented ways. Whereas sports networks' forays across platforms, as in fantasy sports mobile applications, largely preserve television's "role as the site of 'mass' audience," alternative telecasts instead fracture the "communal" engagement that has long defined sports television by offering audiences multiple versions of the same event. Beginning by examining the causes of this shift, this article contrasts the rise of second screen experiences with the rise of alternative telecasts, first analyzing how these expanded telecasts reflect sports television's move into the post-network era and then explaining how they are not only meant to personalize the sports television experience and signal the significance of an event, but also strengthen networks' brands. Next, the article discusses the implications of alternative telecasts, exploring how, in 
further fracturing the communal engagement of sports television, they may undermine sport's capacity to build shared connections and, relatedly, how they intersect with the politics of gender, race, class, and age.

\section{The Rise of Alternative Telecasts}

As media scholars have extensively documented, television has undergone significant changes over its relatively short history as a medium, particularly in recent decades. Lotz (2014), for instance, has influentially detailed how the norms and practices of television have shifted across several distinct eras, tracing, for example, the changes associated with the rise of cable broadcasting and, more recently, the ramifications stemming from the growing significance of internet distribution. One drastic change in the television experience in the most recent eras of television has been the increasing untethering of television from traditional limitations of space and time. Television is not only becoming unbound from the linear schedule that has long dominated the medium, especially considering the rising prominence of streaming services that allow for on-demand viewing, but also is an increasingly portable medium thanks to the spread of mobile viewing devices. Such spatial and temporal untethering contributes to Lotz's (2014) argument that the television experience has grown more and more fractured, having become increasingly distinguished by niche audiences exercising new control over when and where they watch.

Scholars have approached television's fracturing from several angles. Some, for instance, have explored how the growing number of television outlets has played a role in the changing nature of everything from programming strategies to network branding to representational practices (Sender, 2007; Himberg, 2014; Christian, 2018). Others, meanwhile, have been interested in analyzing television's spread beyond the traditional confines of the fixed, living room set. A particular interest has been the rise of "second screen" experiences in which audiences watch television programming on one device while simultaneously using companion devices to complement their viewing. Documenting the industry's embrace of the second screen, Lee and Andrejevic (2014) detail the many attempts by television networks to take advantage of complementary devices, as in ABC's experiments with companion apps for programs like Gray's Anatomy and Academy Awards ceremony, as well as the many attempts to encourage 
viewers to use social networks, like Facebook, Snapchat and Twitter, to engage with television programming by communicating with other viewers online.

Because second screen experiences have largely revolved around exchanges between viewers, Lee and Andrejevic (2014) point out that it is "mediated live events - those that are shared remotely by large audiences," as in presidential elections and award shows, that have best lent themselves to second screen experiences (p. 42). "Viewing itself," they observe, "needs to be turned into something that shares the logic of the event: a sense that others are participating at the same time" (p. 42). They summarize, "Commenting on the on-screen action is not quite as fun when no one else is watching” (p. 43). Indeed, in recent years scholars have continued to point to the importance of liveness in facilitating second screen experiences in genres as varied as the primetime soap opera and reality TV (Patterson, 2018; Stewart, 2019).

Given the strong relationship between liveness and second screen engagement, it is no surprise that sports television programming has been a prime site for second screen experiences and, accordingly, scholarly explorations of this phenomenon. As mentioned above, Johnson (2009a) has documented how sports content has rapidly extended across platforms. She details, for example, how CBS has used its CBSSports.com website to offer features like video highlights, fantasy leagues, and “interactive' contests" like polls - features that viewers can simultaneously use while watching sports television programming. More recently, Cunningham and Eastin (2017) have documented how the "increasing prevalence of mobile devices" has led to an increase in "simultaneous second screen consumption" (p. 289) around sports television, citing, for instance, sports fans' propensity to use social media platforms while watching sports television programming. Like Johnson, Cunningham and Eastin (2017) also detail the efforts that sports television networks have made to engage viewers across platforms, as in ESPN's use of Twitter hashtags "to attract more viewers and increase engagement" (p. 290) around its flagship SportsCenter program. In recent years, too, other scholars of sport have delved into the specifics of how users engage with certain platforms, such as Snapchat (Spinda \& Puckette, 2018), Twitter (Smith et al., 2019), and WhatsApp (Weimann-Saks et al., 2020).

Although second screen experiences have become more and more important within the sports television industry, scholars have thus far overlooked the fact that sports television broadcasters have also recently undertaken broadcasting experiments that instead focus on offering viewers a choice of alternative telecasts. Turner, for instance, has frequently covered the 
National Collegiate Athletic Association (NCAA) Division I men's basketball championships with alternatives it dubs "TeamCasts." While a traditional telecast of a game airs on TBS, Turner uses two of its other cable outlets, TNT and truTV, to offer alternate versions of the telecast specifically catered to the fanbases of the teams involved in the game. During a 2018 NCAA men's basketball Final Four game between Villanova University and the University of Kansas, TNT telecast a Kansas TeamCast featuring commentary from local play-by-play announcer Dave Armstrong and Kansas alumni Scot Pollard and Rob Riggle, while truTV telecast a Villanova TeamCast similarly featuring commentary from regular Big East play-by-play announcer Scott Graham and Villanova alumni Randy Foye and Kacie McDonnell. Other broadcasters have also focused on offering viewers multiple commentary options, if not across multiple television outlets. While simulcasting National Football League (NFL) Thursday Night Football broadcasts also airing on Fox and the NFL Network, for instance, Amazon has given viewers the choice of either listening to the primary Fox commentary feed or several other alternatives, such as a "Scout's Feed" featuring two former NFL scouts. Meanwhile, on its Twitch video service, which is primarily associated with video game livestreaming, Amazon has offered co-streams of Thursday Night Football featuring commentaries from several of its popular personalities.

Other alternative telecasts have offered not just different commentary teams but also different focuses of analysis. Both Fox and ESPN, for instance, have experimented with offering alternative telecasts revolving around statistical analysis. During the 2014 Major League Baseball (MLB) playoffs, for instance, Fox aired a standard telecast of an MLB playoff game on its flagship broadcast channel while also offering an alternative telecast on cable channel FS1 emphasizing advanced metrics like wOBA, wRC+, and WAR. Some sports broadcasters, too, have ventured into gambling-oriented alternative telecasts. The regional sports network (RSN) NBC Sports Washington, for example, has broadcast traditional telecasts of National Basketball Association (NBA) games on its primary channel while also showing gambling-oriented versions on its secondary outlet, NBC Sports Washington Plus. These betting-specific alternative telecasts have been most noticeably distinguished from the primary telecasts by a wealth of informationrich graphics displaying both game statistics and gambling figures like odds and moneylines. Viacom, meanwhile, recently tried a very different sort of experiment, airing a traditional telecast of an NFL playoff game on CBS while simultaneously broadcasting an alternative version of the game with what might be described as a "children's aesthetic" (Orr, 2021) on the cable channel 
Nickelodeon. The Nickelodeon version of the game, ostensibly aimed at young audiences, featured simplified explanations of the sport's rules, numerous colorful graphics, and frequent references to Nickelodeon properties like SpongeBob SquarePants.

As previously mentioned, ESPN has been the most aggressive pursuant of alternative telecasts. ESPN has not just aired a wider variety of programming using alternative telecasts, but also devoted more airspace to its alternative telecasts. ESPN's experiments began in 2006 with alternative telecasts dubbed "Full Circle." The very first "Full Circle" event was a men's college basketball game between Duke University and the University of North Carolina, with ESPN's flagship channel airing a traditional telecast of the game and other ESPN outlets airing alternative telecasts, including an ESPNU feed solely fixed on Duke's student fans (ESPNU Full Circle, 2006). In the following years, "Full Circle" coverage was also used for a range of other events, including an NBA playoff game and the 2007 NCAA Women's Basketball Championship. While the "Full Circle" telecasts received mixed reviews (Stewart, 2006) and ESPN discontinued the "Full Circle" telecasts in 2007, the network has recently redevoted itself to alternative telecasts. Relaunching in 2014, many of these alternative telecasts have been dubbed "MegaCasts." Most consistently, ESPN has deployed these MegaCasts in covering the College Football Playoff National Championship. Recently, though, ESPN has expanded its MegaCast offerings, having also chosen to cover several other college football games with MegaCasts, as well as multiple NFL games and NFL drafts. However, not all the company's alternative telecasts have fallen under the "MegaCast" label. As mentioned, for instance, ESPN has, like Fox, offered alternative telecasts focused on statistical analysis. It has not just offered alternative baseball playoff telecasts oriented around advanced metrics, as has Fox, but has also offered alternative NBA telecasts that draw on player tracking technology from the company Second Spectrum. Rather than MegaCasts, the alternative baseball telecasts have been referred to as "Statcast" broadcasts, while the alternative basketball telecasts have been branded as "Full Court Press" experiences.

Media companies' expanding use of alternative telecasts partially has its roots in the television industry's broader embrace of second screen experiences. Although the telecast options for the MegaCasts, for instance, stretch across ESPN's various linear cable channels and many of the telecasts appear to be optimized for a single screen experience, the company nonetheless envisions many viewers using the MegaCast as a multi-screen experience, with the 
various alternative telecasts serving as complements to the traditional telecast on the flagship channel (Deitsch, 2015). Significantly, the many MegaCast telecasts can be viewed using ESPN's website and mobile applications, whether those telecasts are being aired on linear cable channels, like ESPN2 and ESPNU, or on ESPN's online-only ESPN3 and ESPN+ services.

Because all the MegaCast options can be found online, viewers could hypothetically have the traditional telecast of the college football championship playing on their television while simultaneously watching an alternative telecast like the Coaches Film Room broadcast on their mobile devices. Or, as another example, viewers could watch the traditional telecast on their television while using mobile devices to listen to live audio of local commentators featured on ESPN3. Ilan Ben-Hanan, an ESPN executive, promotes such a pairing, commenting, "If you are a hard-core fan of one of those teams and you want to hear your local guy, we're marrying that call to our television pictures" (as cited in Deitsch, 2015). Other quotes from Ben-Hanan reveal just how closely the rise of alternative telecasts relates to the broader rise of second screen experiences. Commenting on ESPN's decision to venture into MegaCasts, he remarks, "It's an opportunity to experiment and appeal to fans who want to consume a game in multiple ways on multiple screens" (as cited in Castillo, 2015). Recalling the justifications attached to second screen experiences, he adds, "We're seeing more and more evidence that when fans sit down to watch TV, they have their mobile device, tablet, and are on social media...We embrace that" (as cited in Castillo, 2015).

Fitting with the industry's broader moves to integrate second screens, there are a number of reasons why media companies might readily embrace viewers watching telecasts across multiple screens. Notably, second-screen experiences allow networks to further monitor their audiences. To that point, ESPN's online properties have been laced with tracking technologies that collect data about visitors - data that can be either used by ESPN or sold to third parties. ESPN's online scoreboard pages, for example, have come with several different trackers that have collected information about, for instance, a user's location and hardware configurations. Similarly, ESPN3 - the aforementioned online video service that streams ESPN's programming, including its alternative telecasts - has also been loaded with several trackers. Alternativetelecast viewers potentially become, to borrow Mark Andrejevic's (2008) phrasing in regard to online message boards, an "instant focus group" (p. 44) for the network. 
Although the rise of second screen experiences begins to explain media companies' enthusiasm for alternative telecasts - particularly for the alternative telecast options that offer only limited camera angles or that are limited solely to audio - most of the alternative telecasts require further explanation. Significantly, most alternative telecasts are designed to be watched as single screen experiences, as indicated by the incorporation of traditional telecast footage. For example, the popular "Coaches Film Room" MegaCast option devotes a large amount of screen space to the game telecast, thereby ensuring viewers do not need a second screen to follow the game. If, too, a company like ESPN was singularly interested in second screen experiences, it could solely host its alternative telecasts on online platforms, rather than still placing them on linear cable channels. What else, then, explains the growth of alternative telecasts?

On a basic level, alternative telecasts exist as remnants - and reminders - of sports television's expansion during the "multi-channel transition" (Lotz, 2014) that saw a dramatic increase in the number of broadcast and cable television outlets. In his comprehensive overview of ESPN's growth into a sports media powerhouse, Vogan (2015) documents how in a relatively short period ESPN expanded from a single cable channel to an expansive media company spread across range of outlets, with ESPN2 launching in 1993, ESPNews in 1996, ESPN Classic in 1996, ESPN Deportes in 2004, and ESPNU in 2005. Similarly, the same era saw other media companies like Fox and NBC spread across a wide array of sports outlets, with Fox taking stakes in channels such as Speed (later to become Fox Sports 1), Fuel TV (later to become Fox Sports 2), Fox Soccer, and Fox College Sports. In recent years, however, the place of smaller cable channels has come into question as an increasing number of television viewers either drop or reduce their cable subscriptions. In light of such pressures, some niche channels have shuttered, while others, including cable sports channels like ESPN Classic, have been de-emphasized in carriage negotiations (Ramachandran and Hagey, 2017). Alternative telecasts allow media companies to promote and use these increasingly tenuous properties in novel ways by stretching expensive, exclusive live rights into spaces typically distinguished by niche content like minor sporting events.

More recently, alternative telecasts have served as indicators of the increasing importance of internet distribution to sports television. As Hutchins and Rowe (2012) suggest, new media technologies have birthed a "new media sport order" (p. 4). "The Internet, Web, and digital media technologies," they argue, "represent the most far-reaching ensemble of changes to the 
media sport cultural complex since the introduction of television" (p. 9). They cite, for instance, the ways that digital media technologies have facilitated a new "digital plentitude" spurred on by "lower barriers of access and cost" (p. 9) that have allowed for the production and distribution of ever more sports content. Hutchins et al. (2019) have also specifically addressed how Lotz's models of internet distribution apply to sports television, suggesting, for example, that streaming services like DAZN and Amazon Prime Video are both "advancing beyond" (p. 988) the norms of the broadcast era - facilitating, for instance, multi-screen consumption - while simultaneously "incorporating and adapting" (p. 988) certain other broadcast era logics, as in the continuing emphasis on liveness. Alternative broadcasts both reflect these arguments and add additional layers to them. While, for instance, alternative telecasts are visible marks of the "digital plentitude" facilitated by internet distribution, particularly as evidenced by the placement of alternative telecasts on sites such as ESPN3 and Twitch, they also raise new questions about the relationship between traditional avenues of distribution and internet distribution. More specifically, alternative telecasts suggest that sports television's move towards internet distribution is not a simple story of online video either directly replacing or complementing traditional broadcasts, but rather a more complex one that reflects the fact that media conglomerates and sports organizations are asking how to optimize a media landscape replete with both older linear television outlets and newer online platforms.

Beyond their ability to serve as potent symbols of sports television's arrival at a media crossroads, there is more to be said about the specific content and corporate strategies enabled by alternative telecasts. For one, alternative telecasts, like most second screen experiences, potentially allow for more personalized viewing experiences. As in the case of many second screen experiences, it is certain niches of viewer that are particularly well-served. Many of ESPN's MegaCast options, for example, are aimed at especially committed groups of football fans. The "Coaches Film Room," for instance, is targeted at viewers looking for tactical discussions, while the "Finebaum Film Room" is geared specifically toward fans of teams in the Southeastern Conference (SEC). On that note, Ben-Hanan mentions a goal of the MegaCasts is to "super-serve the hard-core fan" (as cited in Deitsch, 2015). Again, though, the alternative experience is unique - fans are not just granted the opportunity to use a second screen to complement the traditional broadcast, but also the opportunity to completely substitute the traditional telecast. This type of personalization offers potential advantages to networks by 
allowing them to sell highly targeted advertising across their various outlets. Mike McCarthy, formerly the president of MSG Networks, hypothesizes of alternative telecasts, "Those folks that are so personally engaged with the content being delivered are far more likely, it would seem to me, to activate with one of the sponsors that that are hitting them" (as cited in Weprin, 2014).

In addition, companies also point to alternative telecasts as a way of signaling the significance of an event. Ben-Hanan comments of MegaCasts, "It's the opportunity to make a big event feel bigger" (as cited in Deitsch, 2015). Similarly, an ESPN press release states the MegaCast's origins lay in making "a big game even bigger" (Volner, 2018). The goal, in other words, is to use the many alternative broadcasts to build excitement for an event, with the many viewing options serving as markers of the event's magnitude. Under this logic, the network succeeds whether or not audiences tune into the many alternative telecasts. Rather, the network succeeds if the presence of the alternate telecasts convinces viewers of the importance of the event.

Media companies are also keen to position alternatives telecasts as opportunities to experiment with original ideas and, in the process, push sports broadcasting forward. Ed Placey, an ESPN producer, comments that the college football Megacasts are "are exploratory and [innovative]" (as cited in Volner, 2018). He adds that MegaCasts represent "a safe playground" (as cited in Volner, 2018). Similarly, Ben-Hanan remarks, "What we get out of the MegaCast is the opportunity to experiment and innovate" (as cited in Deitsch, 2015). Moreover, Ben-Hanan points to specific alternative telecasts as being particularly novel. Of an ESPN3 feed solely filmed from above the field, he remarks, "That wasn't intended to be a huge driver, but it was a really cool thing" (as cited in Ourand, 2014). Similarly, he calls an ESPNU "ESPN Voices" broadcast, featuring ESPN personalities from other sports, "a fun experiment" (as cited in Deitsch, 2015). Other networks have used similar language. Craig Barry, an executive at Turner Sports, remarks of their college basketball TeamCasts, "They are there to be a creative and innovative take on a unique and new way of producing an individual telecast of the Final Four." He adds, "We are always looking to be more innovative" (as cited in Turner Sports' Craig Barry breaks down the art of the Teamcast, 2014). Similarly, Turner Sports President David Levy comments, "We think it is innovative and it's all about innovation" (as cited in Deitsch, 2017). These sorts of discourses of innovation can be quite helpful to networks' brand-building efforts. As Vogan (2015) explains, sports media is "traditionally considered to be less thoughtful 
and refined than other genres" (p. 2). As he notes, though, ESPN has continually worked to distinguish itself as something less "ordinary" (p. 2). The network, of course, touts itself as "The Worldwide Leader in Sports." Moreover, as Vogan details, it has "strategically engaged practices considered more sophisticated than run-of-the-mill sports media" (p. 3). Perhaps most notably, ESPN has aggressively marketed its 30 for 30 documentaries as the rare example of sports television "quality," highlighting, for instance, the auteur credentials of the 30 for 30 filmmakers. In cultivating this aura of "quality" around the 30 for 30 pieces, ESPN consistently attempts to "distinguish the series, and, by extension, ESPN, from other sports media" (Vogan, 2015, p. 8).

Although alternative telecasts do not have the same "aura of refinement" (Vogan, 2012, p.139) as do documentary films like those in the 30 for 30 series, these expanded telecasts are undoubtedly another way for ESPN to distinguish itself from other sports media. In promoting the MegaCasts as "innovative," ESPN figures again attempt to separate the network from its competitors, emphasizing ESPN's unusual willingness to take risks and push against the typical conventions of sports television. To repeat, Vogan (2015) explains that ESPN's push towards "sophistication" is meant to separate the network from the "ordinariness" or sports media. Perhaps even more directly, the language attached to the MegaCasts, as in the frequent references to their "experimental" nature, works to accomplish this goal. In a further parallel to how ESPN promotes efforts like the 30 for 30 series, ESPN also emphasizes that MegaCasts are not intended to drive higher ratings. Ben-Hanan, for instance, argues the alternative MegaCast telecasts "are really meant to be additive and a lot less about what kind of eyeballs they bring in" (as cited in Deitsch, 2015). He elaborates that experimentation matters "more than the ultimate Nielsen rating" (as cited in Deitsch, 2015). As Vogan (2012) notes, ESPN has often worked to distance 30 for 30 films from the commercial associations of sports television, as exemplified by the network's decision to initially air many of the 30 for 30 films without commercial interruption. By emphasizing that its alternative telecasts are not intended to produce increased ratings, the network again attempts to cultivate a perception that it is not solely motivated by commercial interests and, accordingly, that it exists beyond the norms of sports media.

\section{A Newly Fractured Audience}

The above section has detailed the industrial contexts that have shaped the rise of alternative telecasts, explaining how their spread is rooted both in broader changes in the sports 
television landscape - e.g. the rise of internet distribution - and specific attempts by sports media companies to leverage their abilities to extend across multiple outlets. What has not yet been examined, though, are the broader ramifications of these expanded telecasts. Although alternative telecasts have thus far been relatively few and far between, they carry with them the potential to greatly transform sports television's place within both the sports media landscape and American culture. More specifically, alternative telecasts carry with them the potential to alter sports television's relationship to its audiences, making it a more individuated - and thus cloistered - experience.

As Johnson (2009a) writes, sports television is often said to be a partial remnant of network-era television. As previously mentioned, the television industry has had to come to grips with an increasingly fragmented audience. To repeat, audiences are watching increasing amounts of programming across an increasing number of devices at increasingly disparate times. Although sports television has not existed outside of this fragmentation - note, for instance, the rise of niche online sports platforms - much of sports television is said to resist this fracturing by continuing to garner large live audiences. Because of this, sports have continued to attract sizable rights fees. Johnson (2009a) quotes former Fox Sports president Ed Goren, who says, "We invested billions of dollars in sports rights ... with the belief that, as we move forward with more options for people, and as the television universe gets more and more diverse, the one segment of network television that would continue to be must-see TV and would continue to deliver large audiences would be the major sports events because that's where the water-cooler talk will be" (p. 114). This quote reinforces that sports television's continuing ability to attract large audiences does not just lend it great commercial importance, but also great cultural importance by retaining the mythic status of "water-cooler talk." As Johnson (2009a) writes, "Sport on television stands as a shared cultural realm through which we safely encounter and struggle with 'our most prevalent concerns, our deepest dilemmas"” (p. 115).

As Johnson (2009a) further explains, though, the extension of sports media content across platforms has allowed sports television to not just embody network-era programming, but also to become "quintessential post-network-era" programming, too (p. 115). While much of sports television retains the ability to garner sizable live audiences, sports television is also increasingly able to deliver personalized experiences, as in the second screen experiences mentioned above. She argues, then, "Sport programming represents a symbolic and actual 'bridge' between 
network-era practices and post-network realities" (p. 116). Continuing, she elaborates, "It represents a unique hybrid or articulation between network television's traditional role as the site of 'mass' audience, communal, national spectacle (television as the home of larger-than-life events presented with the best view possible) and the post-network era's characteristic proliferation of content and its co-branded migration between media forms" (p. 116).

While Johnson's argument does much to explain how second screen experiences have transformed sports television's place within the media landscape, her account does not quite cover the emergence of alternative telecasts. Rather than personalize the sports television experience by extending content across digital platforms, alternative telecasts personalize the sports television experience largely by extending content within the traditional television space. This is significant because whereas second- screen experiences preserve sports television's ability to collect "mass" audiences by offering complementary content on digital devices while continuing to prioritize the place of the traditional telecast, alternative telecasts instead offer audiences multiple telecasts of the same event, thereby fracturing the shared forms of engagement that have long defined sports television.

There are several consequences to sports television moving away from serving a mass audience. For one, scholars, including Andrejevic (2019) and Couldry and Turow (2014), have suggested individuated media may have larger ramifications for democratic society. Andrejevic (2019) explores how the shift towards the "automated customization of content" (p. 47) has helped undermine "the background conditions for democratic deliberation" (p. 49). More specifically, he argues that as individuals increasingly consume algorithmically tailored media offering "personalized windows into the world" (p. 56), it becomes harder for them to develop a sense of shared understanding with others - shared understanding that undergirds the "civic disposition required for democratic self-governance" (p. 45).

In a similar vein, Couldry and Turow (2014) detail how advertisers are moving away from traditional outlets, like print magazines, aimed at large audiences. Rather, they are taking "personalized" approaches reliant on big data technologies to help them more precisely target viewers. Video streaming services like Hulu, for instance, allow advertisers to use demographic and tracking data to aim their commercials at specific viewers. Different viewers streaming the same show, then, may end up receiving varying advertisements. While such personalization may be a boon for many corporations, like Andrejevic (2019), Couldry and Turow (2014) worry 
about the consequences for society-at-large. More specifically, they suggest that democracies require citizens to have shared reference points that allow them to recognize a "common social and political space" (p. 1711). However, the personalization of ads - and, moving forward, the personalization of other pieces of media - may "erode" that shared "system of reference" ( $p$. 1711). They explain, "Media's capacity to circulate material that builds connections between otherwise diverse groups is not helped, but rather undermined, by the pressures toward personalization" (p. 1722). They warn, then, about a societal "landscape that has been cleared of one basic ingredient of democratic life: the reliable and regular exchange of common ideas, facts, and reference points about matters of common concern" (p. 1722).

Given Couldry and Turow's (2014) emphasis on shared "ways of living," they may find the rise of alternative sports telecasts to be even more troubling than the rise of personalized ads. Returning to the question of "water-cooler talk," sports television - even as it has fragmented across a growing number of cable and online outlets - has perhaps offered the most consistently shared "system of reference" within the media landscape, with live sporting events continuing to dominate year-end ratings and to provide ample fodder for social media exchanges. The fracturing of these events into multiple audiences each watching their own tailored versions of the event, then, would appear to have more severe consequences for "democratic life" than the personalization of ads. With one viewer watching a college basketball game by way of a traditional game broadcast and others watching by way of a locally-oriented telecast or a statistically-focused telecast, there are fewer people partaking in the same "collective experience."

That it is particularly large events like the College Football Playoff National Championship that have been most likely to see alternative telecasts makes this split even more noteworthy. A number of scholars have noted the significant role of television broadcasting, particularly of major sporting events, in fostering senses of community. As Dayan and Katz (1992) argue, major media events, including the "high holidays" (p. 206) of sport, offer and affirm "shared membership in a national or international community" (p. 197). They continue: "All those within reach of a television set are simultaneously and equally exposed, and they share that knowledge that everyone else is too. Technology here allows the spirit of communitas to overcome the divisions inherent in "organic solidarity"' (p. 197). 
Similarly, Brookes (2002) has written that sports broadcasts "contribute to a sense of shared belonging" (p. 87). Alternative telecasts, however, risk breaking the sense that others are sharing in the same televisual experience and, as such, part of a larger citizenry. For example, a viewer watching the College Football Playoff National Championship by way of the "Coaches Film Room" telecast on ESPNU can no longer feel confident that they are part of the same experience as someone watching the "Field Pass" telecast on ESPN2. Such an observation is not meant to valorize sport's role in sustaining a shallow "logic of consensus" (Butterworth, 2020), but rather, in line with Andrejevic (2019) and Couldry and Turow (2014), to suggest that the fragmentation of major events could play a role in eroding the shared social space that undergirds democracy contestation and dissent included.

On top of these concerns about what alternative telecasts might mean for the health of the public sphere, the rise of these new broadcasts also intersects with the politics of gender, race, class, and age. It might first be mentioned that alternative telecasts have the potential to be helpful in expanding coverage of sporting events in ways that serve audiences who have been historically underserved by mainstream sports coverage or that challenge traditional representational practices. Amazon, for instance, has offered Thursday Night Football viewers the choice of an all-women commentary team. Women have long been underrepresented on sports television, including in commentary roles (Messner et al., 2000), so such an option breaks with the long-standing norms of the genre, even as the relegation to an alternate option risks marking women commentators as anomalous. That said, alternative telecasts may instead be working in the opposite direction by prioritizing affluent viewers and deepening sports television's skewed representational norms.

First, it can be asked who is being targeted and served as part of alternative telecasts. In an analysis of ESPN original programming, Johnson (2009b) argues that a network's “"convergent' media strategies" come loaded with "presumptions about who 'counts' and what public(s) should be served" (p. 65). That is to say, some demographic groups are valued more than others and it is these valued groups that end up on the receiving end of the network's attention and financial investments. To that point, a former ESPN executive has suggested that the "customization" of alternative telecasts will eventually "lend itself to more premium offerings" (as cited in McCarthy, 2020). There is also a related question of access, as alternative telecast options have typically been offered on outlets with smaller reach. In the case of Fox's 
analytics-focused telecast, for example, the main telecast aired on Fox, which is available to all viewers, while the alternative telecast aired on FS1, which necessitates a cable package and only reaches $71 \%$ of households with televisions ("How much bigger is ESPN than FS1?," 2017). Thus, alternative telecasts may not only be specifically tailored to relatively narrow groups of viewers, but they may also be unavailable to other viewers. As Johnson (2009b) suggests, such issues of targeting and access deserve particular attention in the case of sports television, for it has traditionally been relatively accessible. The rise of alternative telecasts, of course, does not necessarily mean the end of the mass appeal of sports - rather they represent an attempt to simultaneously draw both mass audiences and niche audiences - but they do deserve scrutiny for their implicit valuing of certain niches over the many others that compose the wider broadcast audience.

Second, while the example of Amazon's all-women commentary team reveals the potential of alternative telecasts to break with the problematic representational practices of the genre, other alternative telecasts point to their potential to uphold, or even worsen, those practices. As mentioned above, a number of alternative telecast options have focused on offering statistically-driven analysis. Troublingly, these alternative telecasts have almost exclusively positioned white men as the authorities on the new data-driven approaches to sport. The datadriven alternative baseball playoff telecast that aired on FS1, for example, featured a desk of several white men at the control of the new technological systems and metrics prioritized by the broadcast. Similarly, ESPN's Statcast baseball telecasts, its "Full Court Press" basketball telecasts and its MegaCast football telecasts have all also placed white men at the center of statistical analysis.

The skewed representation of these broadcasts is not only worrying because it reinforces sports television's long-standing tendency to overrepresent white men (Messner et al., 2000; Turner, 2009), but also because it may contribute to racial and gender biases currently wracking the wider sports industry. As several media members, including Bomani Jones (Chotiner, 2019a) and Jalen Rose (Chotiner, 2019b), have noted, there appear to be racial overtones in the sports analytics discourse. To that point, in investigating the NBA's lack of Black coaches, journalist Howard Beck (2015) writes, "Some coaches blame teams' embrace of analytics - a theory that suggests black coaches are perceived as either less intelligent or less willing to adapt.” Beck (2015) quotes media scholar Todd Boyd, who says, "I think there's this perception, perhaps 
unconscious and perhaps unspoken, that a lot of black guys just aren't smart enough to do the job. And when you throw something like analytics in the mix, it adds to that even more." In continually positioning white men as analytics experts, alternative telecasts are potentially reinforcing such biases.

In the coming years, it is unlikely that alternative telecasts will become everyday sports television experiences. Their infrequency, though, does not detract from their potential importance to the sports television industry and sports television's place within society. As sports television has shifted from the "network era" to the "post-network era" (Lotz, 2014), it has managed to largely retain its traditional position within U.S. culture. Even as audience fragmentation has become the norm across the media landscape, sports television has continued to exist as the rare space for mass audiences. What this article has documented, though, is that alternative telecasts - even while sharing tendencies with second screen experiences - represent a distinct break. Alternative telecasts, rather than preserving the mass audience, splinter it into niched subsets. Such splintering represents a challenge to sports television's role within society and raises additional questions about how the continued fracturing of sports television will affect the relationship between the genre and its audiences. 


\section{Works Cited}

Andrejevic, M. (2008). Watching Television Without Pity: The Productivity of Online Fans. Television and New Media, 9(1), 24-46.

Andrejevic, M. (2019). Automated Media. Routledge.

Beck, H. (n.d.). Where Are All the Black NBA Coaches? Bleacher Report. Retrieved November 6, 2015, from http://bleacherreport.com/articles/2584463-where-are-all-the-black-nbacoaches-examining-a-sudden-silent-disappearance

Brookes, R. (2002). Representing Sport. Bloomsbury.

Castillo, M. (2015, January 12). ESPN Is Airing the College Football Championship in 12 Different Ways. Adweek. http://www.adweek.com/tv-video/espn-bringing-you-tonightscollege-football-championship-12-different-ways-162324/

Chotiner, I. (2019a, June 6). Jalen Rose Has a Problem with Basketball Analytics. The New Yorker. https://www.newyorker.com/news/q-and-a/jalen-rose-has-a-problem-with-basketballanalytics

Chotiner, I. (2019b, June 17). Bomani Jones on the N.B.A., Analytics, and Race. The New Yorker. https://www.newyorker.com/news/q-and-a/bomani-jones-on-the-nba-analytics-andrace

Christian, A. (2018). Open TV: Innovation Beyond Hollywood and the Rise of Web Television. NYU Press.

Couldry, N., \& Turow, J. (2014). Advertising, Big Data, and the Clearance of the Public Realm: Marketers' New Approaches to the Content Subsidy. International Journal of Communication, 8, 1710-1726.

Cunningham, N. R., \& Eastin, M. S. (2017). Second Screen and Sports: A Structural Investigation Into Team Identification and Efficacy. Communication \& Sport, 5(3), 288-310.

Dayan, D., \& Katz, E. (1992). Media Events. Harvard University Press.

Deitsch, R. (2015, January 11). TV guide for Oregon-Ohio State; Michaels, Collinsworth help out NFL. Sports Illustrated. https:/www.si.com/more-sports/2015/01/11/oregon-ohio-statetv-guide-michaels-collinsworth-nbc-goodell

Deitsch, R. (2017, March 12). TV Guide to watching March Madness. Sports Illustrated. https://www.si.com/tech-media/2017/03/12/ncaa-tournament-cbs-turner-broadcastingcoverage-media-circus 
ESPNU Full Circle. (2006, February 27). ESPN.Com. http://www.espn.com/collegesports/news/story?id $=2347040$

Himberg, J. (2014). Multicasting: Lesbian Programming and the Changing Landscape of Cable TV. Television \& New Media, 15(4), 289-304.

How much bigger is ESPN than FS1? - August 2017 Cable Coverage Estimates. (2017, August 2). Sports TV Ratings. https://sportstvratings.com/how-much-bigger-is-espn-than-fs 1-august2017-cable-coverage-estimates/8280/

Hutchins, B., Li, B., \& Rowe, D. (2019). Over-the-top sport: Live streaming services, changing coverage rights markets and the growth of media sport portals. Media, Culture \& Society, 41(7), 975-994.

Hutchins, B., \& Rowe, D. (2012). Sport Beyond Television: The Internet, Digital Media and the Rise of Networked Media Sport. Routledge.

Johnson, V. E. (2009a). Everything New is Old Again: Sport Television, Innovation, and Tradition for a Multi-platform Era. In A. D. Lotz (Ed.), Beyond Prime Time: Television Programming in the Post-Network era (pp. 114-137). Routledge.

Johnson, V. E. (2009b). Historicizing TV Networking: Broadcasting, Cable, and the Case of ESPN. In J. Holt \& A. Perren (Eds.), Media Industries: History, Theory, and Method. WileyBlackwell.

Lee, H. J., \& Andrejevic, M. (2014). Second-Screen Theory: From the Democratic Surround to the Digital Enclosure. In J. Holt \& K. Sanson (Eds.), Connected Viewing: Selling, Streaming, and Sharing Media in the Digital Era (pp. 40-61). Routledge.

Lotz, A. D. (2014). The Television Will Be Revolutionized (Second Edition). NYU Press.

McCarthy, M. (2020, January 13). Why ESPN Bets The House on College Football "MegaCast." Front Office Sports. https://frntofficesport.com/espn-megacast/

Messner, M. A., Dunbar, M., \& Hunt, D. (2000). The Televised Sports Manhood Formula. Journal of Sport and Social Issues, 24(4), 380-394.

Orr, C. (2021, January 10). The Nickelodeon broadcast was a reminder that football doesn't have to be so serious. Sports Illustrated. https://www.si.com/nfl/2021/01/11/nfl-playoff-gamenickelodeon-broadcast-not-too-serious 
Ourand, J. (2014, January 8). ESPN Has No Current Plans For Another “Megacast,” But Multiple Feeds Coming Again. SportsBusiness Daily. https://www.sportsbusinessdaily.com/Daily/Issues/2014/01/08/Media/Megacast.aspx

Patterson, E. (2018). Must tweet TV: ABC's\# TGIT and the cultural work of programming social television. Transformative Works and Cultures, 26.

Ramachandran, Shalini, \& Hagey, K. (2017, March 21). Small Cable Channels You Pay forBut Don't Watch-Are Dying. Wall Street Journal. https://www.wsj.com/articles/smallcable-channels-you-pay-forbut-dont-watchare-dying-1490111102

Sender, K. (2007). Dualcasting: Bravo’s Gay Programming and the Quest for Women Audiences. In S. Banet-Weiser, C. Chris, \& A. Freitas (Eds.), Cable Visions: Television Beyond Broadcasting (pp. 302-318). NYU Press.

Smith, L. R., Pegoraro, A., \& Cruikshank, S. A. (2019). Tweet, Retweet, Favorite: The Impact of Twitter Use on Enjoyment and Sports Viewing. Journal of Broadcasting \& Electronic Media, 63(1), 94-110.

Spinda, J. S. W., \& Puckette, S. (2018). Just a Snap: Fan Uses and Gratifications for Following Sports Snapchat. Communication \& Sport, 6(5), 627-649.

Stewart, L. (2006, September 6). ESPN 'Full Circle' Doesn't Square With the Viewers. Los Angeles Times. http://articles.latimes.com/2006/sep/06/sports/sp-espn6

Stewart, M. (2019). Live tweeting, reality TV and the nation. International Journal of Cultural Studies, 23(3), 352-367.

Turner, J. S. (2014). A Longitudinal Content Analysis of Gender and Ethnicity Portrayals on ESPN's SportsCenter From 1999 to 2009. Communication \& Sport, 2(4), 303-327.

Turner Sports' Craig Barry breaks down the art of the Teamcast. (2014, April 4). Cynopsis Media. http://www.cynopsis.com/story/turner-sports-craig-barry-breaks-down-the-art-of-theteamcast/

Vogan, T. (2015). ESPN: The Making of a Sports Media Empire. University of Illinois Press. Volner, D. (2018, January 8). Fifth Year of MegaCast is More Mega Than Ever. ESPN Front Row. https://www.espnfrontrow.com/2018/01/fifth-year-megacast-mega-ever/

Weimann-Saks, D., Ariel, Y., \& Elishar-Malka, V. (2020). Social Second Screen: WhatsApp and Watching the World Cup. Communication \& Sport, 8(1), 123-141. 
Weprin, A. (2014, December 1). The age of the microcast. POLITICO Media. http://politi.co/21pL3oK 